\section{The Slocum Mission}

Narrative and Illustration

By Henry Stommel

$\mathrm{I}_{\mathrm{T}}$ $T$ IS DIFFICULT to realize that twenty-five years have passed since I first came to the Slocum Mission Control Center on Nonamesset Island, one of the Elizabeth Islands, in 1996. I was a post-doc in physical oceanography, and the Department of the Environment had just acquired the island from the descendants of a sea captain prominent in the China trade of the early nineteenth century. The government acquired Nonamesset to establish the World Ocean Observing System [WOOS], a facility capable of monitoring the global ocean, using a fleet of small neutrally-buoyant floats called Slocums that draw their power from the temperature stratification of the ocean. Nonamesset Island was chosen partly because it is isolated from the mainland of Cape Cod, but mostly because it is close to the Woods Hole Oceanographic Institution, the Marine Biological Laboratory, and a thriving scientific community.

Nestling low in the hills is the Mission Control Center itself, with its satellite antennas. Along the beach, facing Buzzards Bay, there are a few houses for a small permanent staff. Most of the scientific staff commute from their homes in the Upper Cape area, reaching Nonamesset by a ferry. There is a large dock at the cove, but the one that the ferry uses is at Sheep-Pen Harbor on the Hole. There are no automobiles on the island. The buildings are connected by footpaths and there is a narrow-gauge railroad for moving supplies from the docks to the facilities. For the most part the island has been left undisturbed. It is in a pristine state of beauty, tranquil beyond the experience of those who swarm about on the mainland.

The Slocum float is named after Joshua Slocum, the Yankee skipper who first went around the world singlehanded in a small sailing vessel. There were Slocums on the Elizabeth Islands before, ever since Peleg Slocum of Dartmouth purchased Cuttyhunk, Nashawena and Penikese in 1693. Whether Joshua was related to them, I never have discovered. But my relationship with Slocums has a different genealogy - a scientific and technical one. Perhaps I should begin by saying what Slocums do.

They migrate vertically through the ocean by changing ballast, and they can be steered horizontally by gliding on wings at about a 35 degree angle. They generally broach the surface six times a day to

Henry Stommel, Woods Hole Oceanographic Institution, Woods Hole. MA, 02543. contact Mission Control via satellite. During brief moments at the surface, they transmit their accumulated data and receive instructions telling them how to steer through the ocean while submerged. Their speed is generally about half a knot. There are military applications for them, but our work in WOOS is unclassified. We have a fairly large fleet of Slocums, about 1,000 . Half are devoted to a program of routine hydrographic observation, much like the meteorologists' upper air network. The rest make soundings of temperature, salinity, oxygen, nutrients, and those geochemically important tracers that the geochemists have been clever enough to find automatic measuring devices and sensors for. The other half of the Slocum fleet is devoted to purely scientific purposes: special research programs carried out under the instructions of academic scientists, by contract. Slocums were originally designed with a 5-year lifetime, but many have been in continuous service at sea for more than 10 years. They are widely dispersed throughout the world's ocean.

Our WOOS center and the Slocum Mission had their start because of the growing concern with monitoring the environment: Is the ocean heating up? Where are the pollutants going? Can we construct theoretical models of the ocean circulation that are useful in predicting the direction of climate change? With a necessarily small fleet of research ships, how could numerous widely dispersed measurements throughout all depths of the ocean be obtained on a routine basis? In 1995, much of the oceanographic community had been involved for 15 years in the World Ocean Circulation Experiment (WOCE), exploring the general circulation of the ocean but still using the technology of the 80 's. For example, one of the keystones of WOCE was the World Hydrographic Program (WHP), which used a single ship per year over a period of 12 years to survey 48 long hydrographic sections, with some repeats. Only six stations each day could be occupied, giving a very low rate of data acquisition compared to what the meteorologists were getting from their upper air network.

A really new method was needed, one that would provide subsurface data on a scale and at a frequency that matched what remote sensing by satellite provided for the sea surface. Multiplying the number of ships by a factor of 100 was economically out of the question. But a pioneering ocean engineer had a different vision of how to garner a harvest of data on a deep-ocean global basis, and this led, after a few vicissitudes, to the Department of the Environment 's determination to support the Slocum Mission and the present deployment of Slocums throughout the world. It has been my career.

So here I am on a lovely October day sitting in the library of Mission Control overlooking Vineyard Sound. On the grass bank outside the window there is a flock of sheep grazing. I have the daily logbooks of those first deployments and experiments made in the early days of Mission Control before me on the 


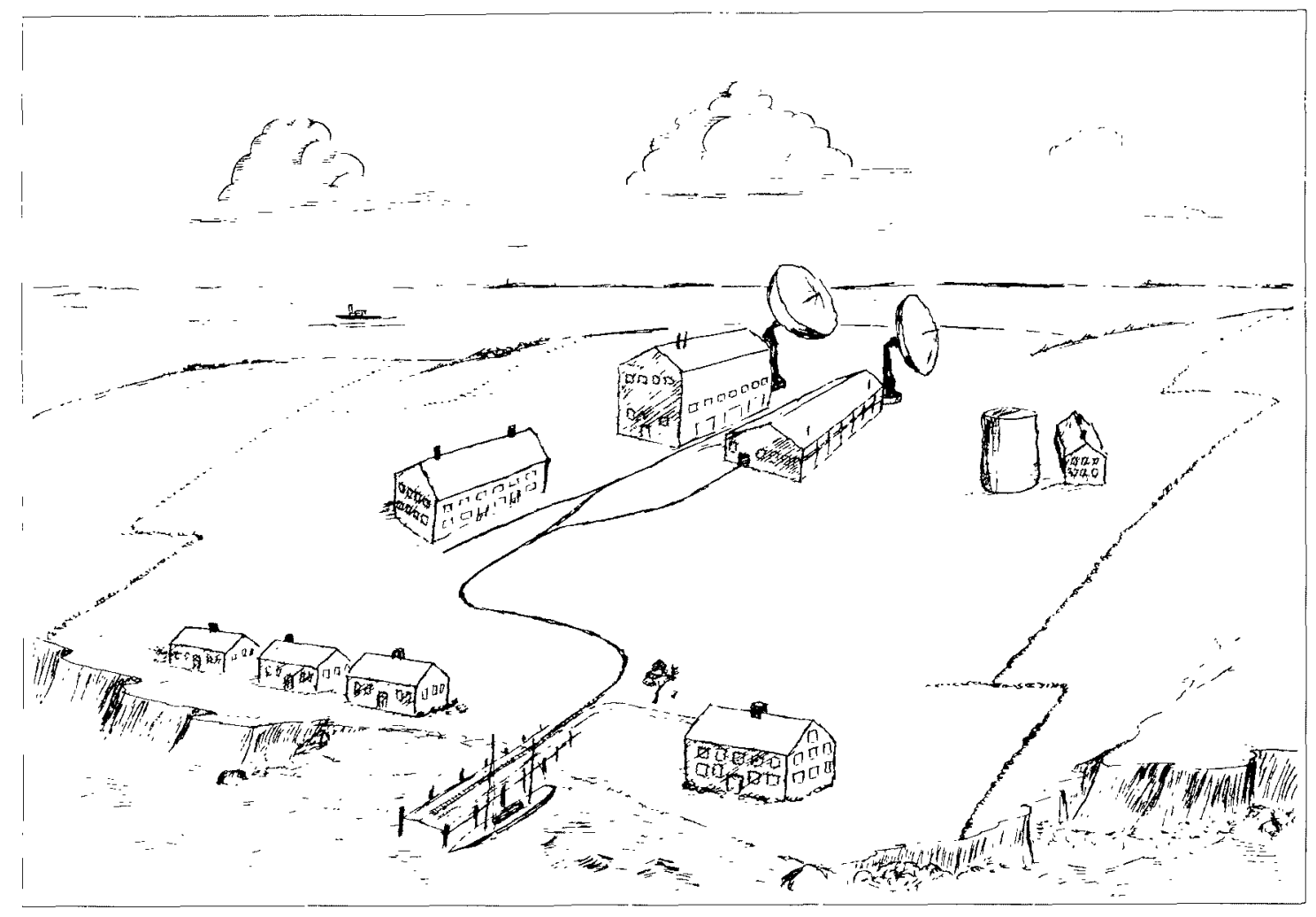

The Slocum Mission Control Center on Nonamesset Island.

table. The assembled staff has asked me to describe the excitement of those early days on a personal level, so that is what I am going to try to do.

As most of you know, the backbone of our climate monitoring capability is our permanent fleet of 480 Sentinel series of Slocums. These are able to occupy, on a monthly basis, all the 48 hydrographic sections that took the WHP 12 years to do once. We acquire data from this widely dispersed network via satellite telemetry. It is something of a wonder to follow the intricate patrol pattern of the Slocums assigned to the various sections. For example, there are ten assigned to patrol a section along $24^{\circ} \mathrm{N}$ in the Atlantic. Each patrols a six degree segment of longitude. Pairs meet once a month to do an intercalibration. Sometimes we schedule an intricate cotillionlike dance of the Sentinel Slocums in which they interchange patrols, thus obtaining, over the course of a year, a complete intercalibration of all Slocums on the section. We also have special Calibration Standard Slocums that wander randomly about the patrol lines, like the inspectors on a subway system, calibrating all Slocums that they encounter.

Each Slocum reports into Mission Control via satellite about six times a day. At each report, conductivity, temperature and depth (CTD) data are transmitted, along with auxiliary tracer data. The satellite also reports the Slocum's position, which informs us how much the float has been set by the ocean currents it encounters and permits its automatic pilot to be reset according to a course-correction algorithm. During the day, the casts terminate at different depths, and sometimes the floats dwell for a period at the bottom of the cast, so it is possible to recover information about the vertical modal structure of the currents.

Thus we have a basic set of Sentinels routinely patrolling the ocean between $50^{\circ} \mathrm{S}$ and $50^{\circ} \mathrm{N}$, equivalent to a fleet of 48 full-time hydrographic survey ships, making no port stops, using no fuel, and by international law exempt from the restrictions on passage through territorial waters exacted of manned vessels. Each day we get about 3000 CTD profiles from our Sentinel fleet.

The prototype Sentinel was launched in 1994, before the Mission Control Center was built, and the little group of originators was still working in the attic of the Bigelow building at the Woods Hole Oceanographic Institution. I can only imagine what the sense of excitement must have been in the attic control center when they started to control the navigation of Sentinel 1 after its launch off Bermuda. According to the logbook, it was decided not to confront the Gulf Stream at the start. The plan was to steer the Slocum as nearly eastward along $32^{\circ} \mathrm{N}$ as could be done, making a highly detailed hydrographic section along the way. With some delays due to interrupted communication, this section took 198 days. It ended off Ifni on the Northwest African coast, where the RRS Discovery had ended her 1957 section long before. The ship managed to obtain 25 casts. Sentinel 1 obtained 3820 casts. On this leg the prototype successfully demonstrated that effective hydrographic station work of a routine nature could be done remotely by an unmanned, unfueled instru-

\section{Each Slocum reports}

into Mission Control via

satellite about six times

a day. 


\section{There is nothing like}

the need to make

decisions to lay bare

areas of ignorance that

are papered over in

textbooks ment package, directed by controllers far away. The atmosphere in the attic must have been ecstaticrather like that in the spacecraft control room when Voyager 2 rendezvoused with the moon of Neptune in August 1989. That first Slocum spawned the whole fleet of monitoring Sentinels that we have in the ocean today.

But Sentinel 1 had further successes. On a return westward section the following year, it encountered a Mediterranean salt-lens eddy. According to the logbook, the eddy was first detected in the velocity structure. It was decided to goeddy chasing. Soon the high salt at $1200 \mathrm{~m}$ depth became evident. Sentinel 1 became trapped by the eddy, but after three revolutions it was shaken loose, and the controllers were now faced with an interesting problem-how to relocate the eddy and implant the instrument package in it again. In those days there was very little information about the nature of the variability of the background current field, and it was difficult to find the eddy. Help was proffered by some numerical modelers. who had set up a dynamical model on the basis of the data obtained during the first three revolutions before the eddy was lost. Their model suggested a general amplitude of pulsation and a direction of drift. As it turned out, the search was successful, and for a further six years, the eddy was tracked, measured and studied as no eddy had ever been before. On the basis of this study. the Mediterranean Water Experiment during the years 2003-2013 was designed and conducted with spectacular successrevealing an unexpected physical process of tracer dispersal, and a bizarre mathematical way of parameterizing it in general circulation models.

One of the naive early experiments with Slocumsbefore the Department of the Environment assumed responsibility for them and built the Nonamesset facility-was the International Round-The-World Race of three Slocums. At the time, the whole idea of participating in a race sounded a little disreputable to the rest of the scientific community, but a sense of adventure reinforced by a lack of alternate funding drove the Slocum advocates to accept the invitation of the New York Yacht Club, and of Australian and French equivalents, to build three Slocums for the purpose. They were controlled from the attic office, but according to instructions received from the three race committees. The U.S. committee had originally suggested that the race be from Bermuda to Bermuda, but it was finally decided to begin and end at Hawaii, since it was suspected to be more difficult to choose good north-south courses in the Pacific than in the Atlantic. Each committee was given the positions of all three Slocums. Because the Slocums did not have to carry CTD and tracer sensors, they cost less than $\$ 100,000$ each, and funds of $\$ 200,000$ a year for the attic control center were guaranteed for five years.

The race was a great popular success. Television programs carried news of the progress of the race on a weekly basis. Lay people became familiar with equatorial undercurrents, western boundary currents, and the Antarctic Circumpolar Current. Mesoscale eddies became a part of everyday language. The National Geographic Society made two television documentaries about the contest. Theoretical pundits offered their advice to all sides. National computer centers confidentially advised their national race committees. Cadets at Annapolis tried to organize a last minute entry of their own. The French won with a spectacular score of 708 days.

The race showed that one could develop skill in programming the Slocums. Having to decide what heading to choose stimulated modelers and descriptive oceanographers to exercise their minds and their computers. As the results of decisions became obvious, knowledge grew, and as knowledge grew, performance improved. The challenge of the race inspired a marvellous exploration of geography. phenomenlogy, dynamical theory, computer programs and technical development. There is nothing like the need to make decisions to lay bare areas of ignorance that are papered over in textbooks. Suddenly one is faced with the practical problem of finding a western boundary current, riding internal Kelvin waves, or traversing an unknown oceanic region, learning about it as one goes.

T IN LATER YEARS, the early U.S.-AustralianFrench race paid handsome dividends. It evolved into our program of Explorer Slocums, today the predominant scientific program of the Mission Control Center. More than 300 Slocums are dedicated to several dozen scientific studies at any one time. There are presently 40 devoted to study of the recirculation regions of both the Gulf Stream and Kuroshio. To date these instruments have collected information for synoptic descriptions and mapping and have gathered statistics about low frequency variability for over 15 years in each region. The result has been a remarkable improvement in physical understanding and numerical modeling in both these regions. Other groups of Slocums study equatorial dynamics, map overflows and western boundary currents in remote oceanic regions, and increase the precision of local data bases, for example.

Some of these Explorer projects have gone on for a decade or more. One of the earliest was a study of the circulation in the equatorial Indian Ocean, suggested in 1988 by a few far-sighted oceanographers. Several Slocums were launched in the western $\mathrm{Pa}$ cific off Mindanao. They were steered into various passages in the Indonesian Archipelago, such as the Banda Sea, and then held in position by gliding against the prevailing currents in such a fashion as to monitor the transport of water from the Pacific into the Indian Ocean through the Archipelago. This part of the project lasted two years, until statistically good transport estimates had been obtained, and then the Slocums explored the water mass front near $10^{\circ} \mathrm{S}$ latitude in the Indian Ocean, in particular that part of the circulation that passes toward the west, north of 
Cape Amber, Madagascar. It was found that most of the time this water flows northward across the equator to join the Somali Current. During later years, it was discovered that intermediate waters escape from the Arabian Sea and manage to move southward across the equator.

The projects that I have always liked best are the ones conceived on the spur of the moment by an inquisitive individual. We try to reserve twenty percent of our Slocums to pursue such sudden inspirations. They are generally the most exciting; they evolve in unexpected ways and reveal new dimensions of the unknown about the ocean. We have used small numbers to follow whale migrations, for example, and to decipher the language of whales. We have conducted explorations in regions where political unrest would hamper the conduct of conventional ship operations. And we always have delighted in being of service to scientists with unusual and new ideas that demand examination. even at the expense of the pressures to expand military obligations and more routine civilian monitoring programs. We have found. over the years, that the payoff in increase of knowledge often is greatest the more unconventional the idea, especially when it conflicts with collective wisdom. This policy has not always been easy to justify to our government sponsors, but they have become accustomed to allowing us to utilize a twentypercent fraction of the observational resources they pay for in these imaginative risky speculative ways. So we have our fun, and they have learned that it pays off.

When I first came to Nonamesset the techniques of graphic displays of data were just emerging from the flat screen of the cathode ray oscilloscope and liquid crystal devices of the late twentieth century. Now, of course, the controller is literally animated. It can be zoomed to any time or space scale, giving the observer the impression of swimming through the ocean, much like being aboard a fictional space ship from one of the old popular television programs. Our control room is a highly versatile submarine. We can observe the data in a vast variety of ways. We can switch from observations to predictions of the great numerical models running elsewhere; we can visualize the interplay and balances between various terms in the dynamical equations as computed from data or models; we can scan the history of our subject; we can project ourselves into the scenarios constructed by the paleo-oceanographers. In short, we can immerse ourselves in an infinite variety of ways of looking at the real ocean and our mathematical abstractions of it. This ability is the result of twenty-five years of accrued observation and skill and understanding. We can call upon the most informed scientific opinion available anywhere in the world. And we have become so accustomed to facile manipulation of this mass of information, we can scarcely imagine the plodding ways of earlier days.

\section{Y}

ESTERDAY I was shooting the breeze with a colleague who has a summer house on Cuttyhunk. The view from his house is spectacular-nearly 270 degrees of horizon-extending from the Bourne Bridge, all along the New Bedford shoreline to Point Judith, and then offshore to Sow and Pigs. There is also a wide view of Vineyard Sound over Canapitset Channel. I guess his view beats what we see from Nonamesset. although I do think ours is rather grand too. But then I walk into our control room, with its panoply of views of the sea.

There are the updated global pictures from the remote sensors on satellites, there the evolving maps of subsurface variables, there the charts that show the position and status of all our Slocum scientific platforms, and I am satisfied that we are looking at the ocean more intensely and more deeply than anyone anywhere else.

\section{Meteorological and Oceanographic Global Observing Networks: a Parallel}

DURING THE THIRTY year interval 1945-1975, the world meteorological community established a considerable network of upper-air observing stations. By the 1970 's, wind observations reported by radiosondes ("rawinds") were widely available for analysis of global atmospheric circulation statistics. For example, in January 1971 , launches from about 600 rawind stations were made twice daily in most cases. The stations were unevenly distributed and concentrated near major land masses, mostly in the Northern Hemisphere. Most of the wind data observations were from altitudes less than $500 \mathrm{mb}$. A few of the mid-ocean stations were, for a while. weather ships, but many of the weather ships eventually were discontinued because of the great expense.

The World Ocean Observing System (WOOS) was installed during the thirty years 1995-2025. The distribution of the Slocum fleet (including the routine Sentinel series and some of the special scientific Explorer series) is not fixed geographically, because the Slocums move about in patterns executing oceanographic sections. On a typical day, the approximately 550 Slocums are distributed on a more or less regular rectangular $5^{\circ}$ $x 5^{\circ}$ grid that covers the major ocean basins from $60^{\circ} \mathrm{N}$ to $60^{\circ} \mathrm{S}$ latitude.

Each Slocum can sample the full range of oceanographic depth six times a day. The data sets are reported at each surface interval by means of satellite telemetry links. Synoptic oceanic features change more slowly than their atmospheric counterparts, so it is possible to optimize the collection of statistically independent data by moving the Slocums around, rather than keeping them stationary.

In this way they can complete interconnected oceanographic sections, with an average individual length of $700 \mathrm{~km}$ every 35-50 days. They collect standard physical and chemical data, and they report current drifts integrated over varying depth ranges. $\square$
The projects that

I have always liked

best are the ones

conceived on the spur

of the moment by an

inquisitive individual. 